\title{
OBSERVAÇÃO PARTICIPANTE: UMA METODOLOGIA PARA CONHECER O VIVER, O ADOECER E O CUIDAR DAS FAMÍLIAS RURAIS*
}

\author{
PARTICIPANT COMMENT: A METHODOLOGY TO KNOW THE LIFE, \\ TO BECOME SICK AND TAKING CARE OF THE AGRICULTURAL FAMILIES \\ OBSERVACIÓN PARTICIPE : UNA METODOLOGÍA PARA CONOCER LA VIDA, LA \\ ENFERMEDAD Y EL CUIDAR DE LAS FAMILIAS RURALES
}

Eda Schwartz**

Ingrid Elsen*we

\begin{abstract}
RESUMO: Este artigo tenta mostrar a observação participante como metodologia de coleta de dados de uma pesquisa que teve como objetivo geral compreender o viver, o adoecer e o cuidar de famílias de uma comunidade rural do extremo sul do Brasil. Tal metodologia mostrou-se adequada, pois permitiu estabelecer laços e relações estreitas com a comunidade, na qual, a principal unidade de interação está ligada pelas relações pessoais mais próximas como a família, os vizinhos e os amigos.
\end{abstract}

PALAVRAS-CHAVE: Família; S aúde rural; O bservação; Cuidado de enfermagem

\section{INTRODUÇÃO}

Para se conhecer o ser humano 'cultural rural', é importante conhecer sua história, compreender suas questões no processo saúde e doença, conhecer a dinâmica e a estrutura do sistema e subsistemas com os quais essa família se relaciona, para, enfim, conhecer o ser humano/família rural e suas necessidades, num ciclo contínuo de construção desse ser humano e de seu espaço/tempo, contribuindo, dessa forma, para a melhoria das condições de vida dessa população. Para tal propus uma pesquisa com base na abordagem Bioecológica de Bronfenbrenner ${ }^{1,2}$, segundo a qual as características das pessoas e do meio ambiente, a estrutura dos cenários ambientais (ambiente rural) e os processos que dentro desse ambiente e entre os indivíduos, devem ser considerados como interdependentes.

A visão Bioecológica do desenvolvimento humano também valoriza a pesquisa em ambientes naturais e a busca de elementos saudáveis ao desenvolvimento, associando-se diretamente aos objetivos de conhecimento e à intervenção em populações de risco. Portanto, ela permite conhecer como as famílias vivem, adoecem e se cuidam num território rural, visto que a família é uma fonte rica de experimentos naturais, e é nesta perspectiva que ela se reveste de importância para esta pesquisa, que possui como foco a família rural e seu sistema de relações.

Neste contexto, optou-se, como metodologia de coleta de dados, pela observação participante, para tentar compreender essa dinâmica das relações do viver, do adoecer e do cuidar das famílias em uma comunidade

Este artigo é parte da tese de doutorado "O viver, o adoecer e o cuidar das famílias de uma comunidade rural do extremo sul do Brasil: uma perspectiva ecológica", orientada pela Prof. - Dr. - Indrid Elsen, defendida em 2002.

** Enfermeira. Doutora em Enfermagem. Professora do Departamento de Enfermagem da Faculdade de Enfermagem e Obstetrícia da Universidade Federal de Pelotas, membro do Núcleo de Estudos e Pesquisas em Enfermagem (NEPEn) e do Laboratório de Estudos Interdisciplinares de Família e Saúde (LEIFAMS).

*** Enfermeira. Doutora em Ciências da Enfermagem. Professora do Programa de Pós-Graduação da UFSC. Coordenadora do LEIFAMS/CNPq/ FUNCITEC 
rural, já que o observador participa em interação constante em todas as situações, espontâneas ou formais, acompanhando ações cotidianas e habituais, as circunstâncias e o sentido destas ações, o que lhe possibilita as interrogações sobre as razões e significados de seus atos ${ }^{3}$.

Para abordar a realidade da família rural como um sistema que se relaciona com outros sistemas, pareceu-me pertinente uma abordagem de natureza qualitativa. Pois a "[...] a pesquisa qualitativa trabalha com um universo de significados, motivos, aspirações, crenças, valores e atitudes, o que corresponde a um espaço mais profundo das relações, dos processos e dos fenômenos que não podem ser reduzidos à operacionalização de variáveis, [...] a abordagem qualitativa aprofunda-se no mundo das ações e relações humanas, um lado não perceptível e não captável em equações, médias e estatísticas "1:21-22.

O material primordial da investigação qualitativa "é a palavra expressa, a fala cotidiana, seja nas relações afetivas e técnicas, seja nos discursos intelectuais, burocráticos e políticos"5:245, visto que as palavras são capazes de registrar as fases transitórias e mais efêmeras das mudanças sociais. A fala, assim, torna-se reveladora de condições estruturais, de sistemas de valores, normas e símbolos e, ao mesmo tempo, possui a magia de transmitir, através do entrevistado/observado, representações de grupos determinados em condições históricas, sócio-econômicas e culturais específicas.

A pesquisa qualitativa é, pois, uma perspectiva que coloca as pessoas no centro, vendo-as de uma maneira holística, favorecendo a compreensão das experiências humanas, tão importantes para profissionais de saúde que se concentram no cuidado, na comunicação e na interação ${ }^{6}$.

Além disso, a pesquisa com enfoque qualitativo não é um atributo que se pode medir, mas "ela se faz presente em uma investigação que ultrapassa os limites 'confortáveis' da precisão cartesiana para 'arriscar', compreender os fenômenos em sua complexidade" ${ }^{\text {7:26. }}$.

S elecionei como metodologia de coleta de dados a observação participante, visto que a mesma facilita captar uma variedade de situações ou fenômenos que não são obtidos apenas por meio de perguntas, uma vez que os indivíduos são observados no próprio contexto, transmitindo o que há na vida real4. Nesta forma de observação, ficamos face a face com os observados e participando com eles no seu ambiente natural e esta aproximação permite a coleta dos dados ${ }^{8}$ em uma variedade de situações ou fenômenos.

Complementando, a observação participante não deve ser um método único, mas uma combinação de vários métodos dirigidos para um fim ${ }^{9}$. Neste sentido foi utilizada consulta a documentos e entrevistas semiestruturadas com os informantes-chaves ${ }^{9}$. Estes são pessoas escolhidas atentamente e propositalmente dentro da cultura ou subcultura, por terem mais conhecimento sobre o assunto ${ }^{10,11}$ objeto da pesquisa.

Esses informantes são utilizados para descrever as normas, valores, crenças e modos de vida da cultura. 0 termo informante é usado para "reconhecer atributos personalizados e a importância dos papéis destas pessoas, em vez do termo impessoal 'sujeitos', que é usado em pesquisa quantitativa"10:47.

Foi utilizado, ainda, para guiar o estudo, como um dos passos da observação participante, o método da enfermeira teórica Madeleine Leininger, também denominado de Modelo de observação, participação e reflexão (O.P.R). 0 modelo de Leininger, derivado da tradicional aproximação participante-observador, usado na antropologia, foi acrescido da fase da reflexão para servir aos propósitos e aos objetivos da pesquisa em enfermagem. Esse método, a perfeiçoado, tem sido utilizado há três décadas por muitos estudantes graduados e enfermeiros brasileiros ${ }^{12,13,14,15,16,17}$, entre outros.

As fases do modelo ${ }^{10,11}$ são as seguintes: num primeiro momento, o pesquisador é levado a devotar um período de tempo fazendo observações. 0 observar, ouvir e registrar são as principais tarefas nesta primeira fase. Ocorre, principalmente, quando o pesquisador está iniciando a entrada no campo.

$\mathrm{Na}$ etapa seguinte, denominada de observação com alguma participação, a observação continua sendo o foco principal, mas o pesquisador já começa a interagir com as pessoas, observando suas ações e falas. O corre o início da participação do pesquisador, no contexto. 
$\mathrm{Na}$ terceira fase, ocorre a participação com alguma observação. Aqui o pesquisador torna-se um participante ativo, conhecedor da situação e do contexto; a observação tende a diminuir.

Já a fase de reflexão possibilita, além da organização e análise dos dados, a confirmação dos resultados com as pessoas e/ou comunidades estudadas. A observação reflexiva significa olhar para trás, recapitulando a situação e todo o processo ocorrido, com uma avaliação completa da situação ou fenômeno. 0 pesquisador reflete sobre todas as descobertas para checar e confirmá-las, primeiramente, com seus informantes chaves.

\section{APLICAÇÃO DA METODOLOGIA}

Descrevo, a seguir, a metodologia proposta para guiar o estudo, fundamentada em diversos autores $3,4,8,10,11$. Em um segundo momento, descrevo como a mesma se concretizou no campo.

Considerando a posição da pesquisadora como observadora, ou seja, "deixa claro para si e para o grupo sua relação como meramente de campo"3:142, este aspecto foi bem esclarecido para a comunidade e as famílias, isto é, sempre foi revelada a condição de minha presença apenas como pesquisadora. Portanto, em alguns momentos, compartilhamos da vida ativa e dos sentimentos das pessoas em termos de relação face a face.

O estudo foi desenvolvido em uma zona rural de um município de Pelotas, com aproximadamente 3.500 hab. As famílias do distrito estudado são formadas por pequenos produtores rurais, de origem alemã e/ou pomerana****. A unidade produtiva familiar tem seu destaque nas plantações de fumo.

\section{IDENTIFICANDO OS INFORMANTES NA OBSERVAÇÃO PARTICIPANTE}

Devido à concepção de família rural como um sistema de inter-relacionamentos com os demais sistemas, as famílias foram observadas, num primeiro momento, quando um dos seus integrantes participava de uma consulta e/ou atividade na unidade básica de saúde. Posteriormente, foram sendo observadas e contactadas nos programas de saúde, em festas religiosas, na vida cotidiana da comunidade e, finalmente, em visitas domiciliares, quando já definidos os informantes/famílias/chaves.

Como informantes-chaves foram incluídos o subprefeito, a "atendente de enfermagem"***** da comunidade, o pastor da igreja protestante "Comunidade Livre"********, que intermediaram o contato com os demais informantes e que também se mostraram receptivos e interessados em participar do estudo. Estes informantes foram importantes para descrever a história e o processo de viver da comunidade.

As demais famílias da comunidade, os usuários da unidade básica de saúde, a equipe multiprofissional da unidade básica de saúde Sol******* e os donos das vendas constituíram os informantes gerais, uma vez que trouxeram, de alguma forma, enriquecimento sobre o viver, adoecer e cuidar das famílias rurais.

Ao se pensar sobre quantas famílias participariam do estudo, utilizou-se o critério que afirma que "o tamanho da amostra é muito mais uma questão de julgamento e experiência na avaliação da qualidade das informações coletadas em relação ao uso destas informações do que o método de pesquisa propriamente dito"18:179. Dessa forma, não existiu um critério numérico, mas teve-se o cuidado de selecionar um número de famílias e de informantes que "fosse capaz de refletir a totalidade nas suas múltiplas dimensões"3:102.

\footnotetext{
**** Pomerano ou pomerânio é originário da antiga Pomerânia. A língua é apenas um dialeto.

***** Era conhecida como "a enfermeira" do local e atuava como figura conhecida na resolução dos problemas de saúde na comunidade.

****** Comunidades livres são assim denominadas porque não são subordinadas à Igreja oficial. Isso se deve aos primeiros tempos de colonização, pois havia dificuldade de conseguirem pastores para as igrejas. Rheingantz, colonizador alemão, providenciou a vinda de jovens seminaristas, que haviam sido reprovados e rejeitados nos seminários europeus, mas que tinham formação religiosa. Quando não conseguiam pastores com formação, fazia-se pastor aquele que entendesse um pouco de como realizar um culto, ou algum membro da comunidade que fosse esclarecido. Prática que permanece até a atualidade.

******* Utilizo o nome fictício "Sol" para denominar o local e a comunidade estudada a fim de manter o anonimato desta.
} 


\section{COLETANDO OS DADOS EM OBSERVAÇÃO PARTICIPANTE}

A coleta dos dados foi feita, utilizando-se, desde consulta a documentos, como prontuários, mapas, registros da prefeitura e subprefeitura, documentos do Instituto Brasileiro de Geografia e Estatística (IBGE), da EMATER e da igreja, até visitas domiciliares, entrevistas semi-estruturadas durante os cuidados prestados na unidade básica de saúde e diálogos com a equipe de saúde e de outros serviços da comunidade, no período de março a novembro de 2001. Como na maioria dos métodos qualitativos, a pesquisadora foi 0 maior instrumento de pesquisa, ou seja, ela constituiu-se no elo entre a realidade observada face a face e a interpretação dos dados.

\section{A PRIMEIRA FASE - A OBSERVAÇÃO}

Constou basicamente de observações e do escutar ativo de tudo que ocorria na comunidade e na unidade básica de saúde. Nesta fase, procurei a direção da Secretaria de Saúde de Pelotas e a direção de enfermagem para expor os objetivos e a importância do meu estudo, assim como solicitar autorização para desenvolvê-lo na unidade básica da comunidade Sol. Nesta oportunidade, indaguei da possibilidade de utilizar o mesmo carro que transportava a equipe para o posto de saúde. Foi-me solicitada, pelo Secretário de Saúde, uma declaração de isenção da Secretaria de S aúde do Município de Pelotas da responsabilidade por possíveis acidentes e/ou danos que pudessem ocorrer durante o trajeto; a mesma foi prontamente encaminhada.

Nesta fase, foram observados: o cotidiano da unidade básica de saúde, seus funcionários, os usuários, os procedimentos realizados, os diálogos entre a equipe e as famílias. Iniciou-se, ainda, a seleção das famílias que fizeram parte do estudo. Um dos fatores que auxiliaram na escolha foi a disponibilidade e a facilidade de comunicação, pelo fato de eu entender o dialeto falado por elas. Este fato facilitou a permissão dada pelas famílias para as visitas às residências, embora ainda com alguma desconfiança. Os contatos com o subprefeito, a "atendente de enfermagem" da comunidade e o pastor também foram iniciados neste período.

\section{A SEGUNDA FASE - A OBSERVAÇÃO COM PARTICIPAÇÃO LIMITADA}

Esta fase ainda conteve períodos de observação, porém já acontecia alguma forma de participação entre a pesquisadora e as pessoas envolvidas no estudo. Na unidade básica de saúde, participava da assistência aos usuários, realizando curativos, vacinas, pré-natal, puericultura. Como nesse período acompanhei o estágio dos alunos da graduação do Curso de Enfermagem e Obstetrícia da Universidade Federal de Pelotas, na disciplina de Saúde Pública, foi-me fácil integrar as atividades de cuidado no dia a dia do serviço. Fizemos parte das equipes que atuaram nas campanhas de controle do Diabete, de Vacinação Nacional e de prevenção da Hipertensão, realizando os procedimentos de coleta para glicemia, verificação de pressão arterial e dando as orientações pertinentes. Nessa ocasião, ouvi muitas histórias, conheci crenças, valores e práticas dos moradores da comunidade.

No mesmo período iniciei a consulta às fichas de atendimentos do posto (FA), para mapear os diagnósticos mais comuns, dos freqüentadores do posto. Constatei ser comum "a doença dos nervos", os curativos por ferimentos causados por instrumentos de trabalho, as lesões músculo-esqueléticas e as gripes/resfriados, ocasionados, provavelmente, por intempéries, devido ao início do inverno na região sul.

Comecei a realizar contato com os informantes, marcando as primeiras visitas domiciliares, as entrevistas com o pastor da igreja evangélica da "Comunidade Livre" e com a "atendente de enfermagem" do local.

Quando da visita ao pastor, este me mostrou o livro de anotações das comunidades que atendia, constando o número de casamentos, batizados, confirmações e falecimentos acompanhados por ele, aquelas anotações só haviam sido iniciadas há dois anos. 
Também nesta fase participei de uma festa da igreja evangélica na sede da comunidade, ocasião em que observei alguns participantes da festa e conversei com os mesmos. Participei, também, de um culto na igreja evangélica.

\section{ATERCEIRA FASE - PARTICIPAÇÃO COM OBSERVAÇÃO}

Neste período a observação foi sendo aprofundada quanto aos aspectos mais específicos como procedimentos do cuidado, higiene, inter-relação com os integrantes das famílias. Participei, em vários momentos, das atividades das famílias a fim de entender seu cotidiano e suas relações. la às lavouras onde estavam plantando fumo, colhendo repolhos, cuidando de animais, arando a terra, e às casas onde prestavam cuidados de promoção da saúde em casos de doença. Nesta fase, ainda continuava a prestar assistência na unidade básica de saúde, pois muitas pessoas me procuravam para que as atendesse, falando em alemão, ou pomerano.

Nas visitas às famílias acompanhei-as em suas atividades diárias: 0 trabalho na lavoura, a plantação de fumo, o trato dos animais e os cuidados com algum dos seus membros. Saliento que essas famílias foram escolhidas porque se dispuseram a auxiliar no estudo e estavam envolvidas no cuidar de um de seus integrantes. Ao mesmo tempo em que acompanhava o cotidiano familiar, fazia entrevistas mais dirigidas sobre os fatos observados, coletava dados a respeito da história da família e realizava junto com eles o genograma.

Nos diálogos e nas entrevistas, tive o cuidado de deixar o entrevistado falar livremente, sem interrupções, "permitindo ao informante interpretar, demonstrar, esclarecer, verificar ou confirmar dados"10:55.

As entrevistas foram realizadas com as famílias que freqüentavam a unidade básica de saúde e ainda com outras, visitadas em seus domicílios. Ao apresentar cada família e seus integrantes, utilizo as denominações que julguei pertinentes, considerando a principal característica de cada uma. Foram realizadas, para a "família Cuidadora", três visitas; para a "família (des)Conectada", nove visitas; para a "família Esperança", sete visitas e para a "família Apoio", nove visitas; totalizando-se, dessa forma, 28 visitas domiciliares. Não estão aqui incluídos os encontros realizados na unidade básica de saúde.

A fim de garantir que o referencial teórico fosse abordado na coleta de dados, elaborei o seguinte quadro para guiar meu trabalho de campo.

\section{QUADRO $1 \square$ RAO RAAORAUAORA $\square$ ADA OODOA}

DOA D DADO

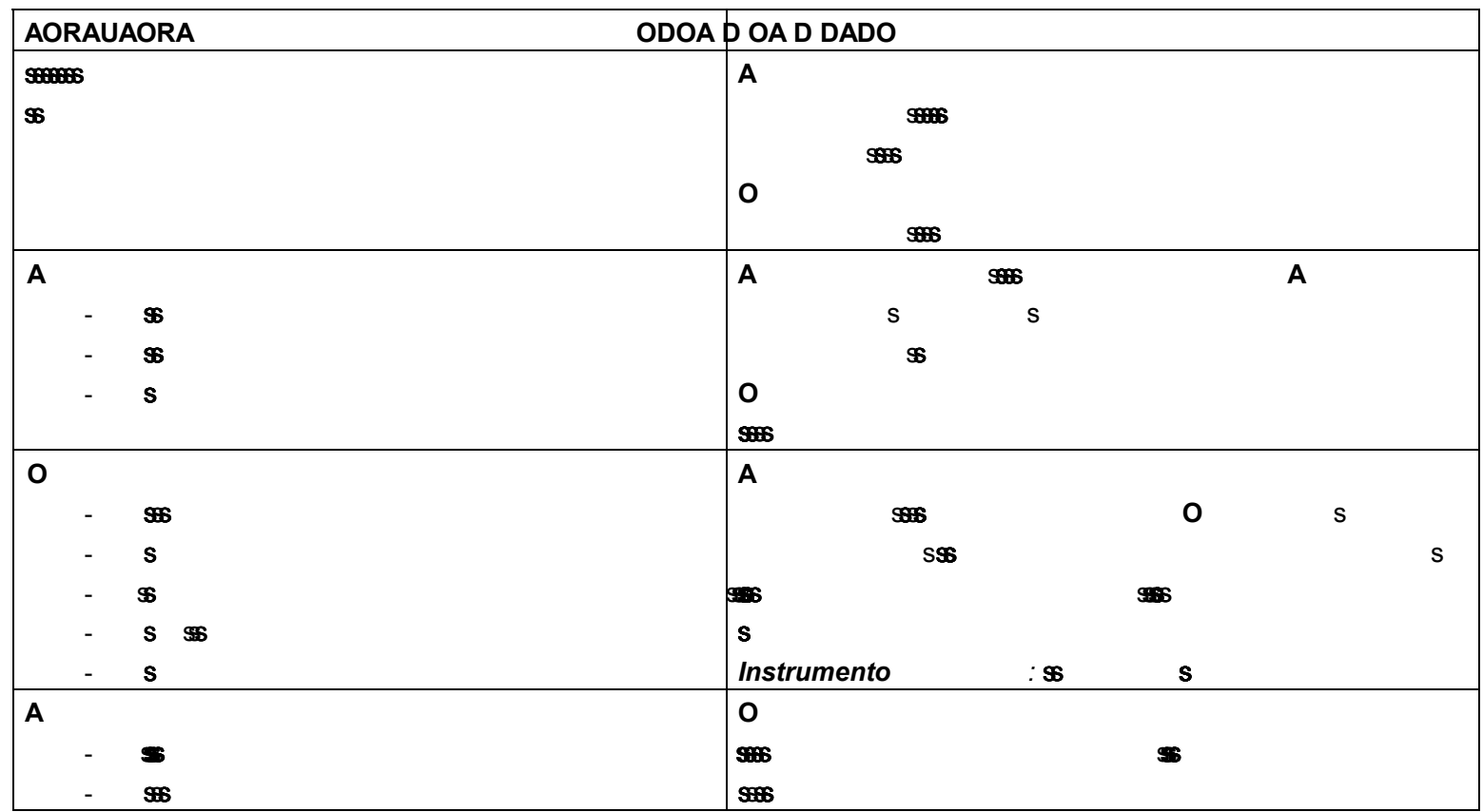




\section{A QUARTAE ÚLTIMA FASE - REFLEXÃO}

A pesquisadora, nesta fase, se encontra com grande parte dos dados e inicia a reflexão sobre os mesmos. É um olhar reflexivo para o processo percorrido, para analisar, confirmar e discutir os dados com as pessoas envolvidas. Embora seja classificada como a última fase, lembro que a reflexão foi feita desde o início do trabalho de campo. Neste período, apenas se intensificou esse processo. Em alguns momentos, quando tinha dúvidas ou precisava confirmar dados, retornava à família ou à unidade básica de saúde para entrevistas mais direcionadas.

\section{REGISTROS NA OBSERVAÇÃO PARTICIPANTE}

As anotações sobre os fatos observados bem como os diálogos foram registrados na forma de diário de campo. No local destinado à observação eram feitas pequenas anotações com palavras chaves e, ao chegar em casa, digitava as informações na íntegra. A descrição de cada dia de visita às famílias levava em torno de três a quatro dias para concluir. As descrições das observações feitas no posto de saúde eram feitas após as descrições das famílias.

Foram registradas no diário de campo, ainda, as minhas impressões pessoais e reflexões. Não utilizei gravador, visto que inibiria a participação dos informantes e, mesmo porque, muitas vezes as conversas eram realizadas durante as rotinas diárias de trabalho e o tipo de tarefas desenvolvidas dificultava o uso desse recurso.

\section{PROCEDIMENTOS ÉTICOS NA OBSERVAÇÃO PARTICIPANTE}

É relevante lembrar que todos os informantes participaram da pesquisa voluntariamente, sendo-Ihes apresentado um termo de consentimento livre e esclarecido, e a autorização para fotografar, que foram lidos e assinados em conjunto, sabendo uma via para guarda e posse da família. No contato com as famílias, além das assinaturas dos termos de consentimento, foi-lhes informado que os dados seriam usados somente para 0 estudo. Os familiares foram informados, também, de que seria mantido o seu anonimato, assim como o da comunidade, utilizando-se nomes fictícios. Os princípios éticos foram baseados no código de Ética dos Profissionais de Enfermagem, de 1993, capítulo IV, artigos 35 e 37 e na resolução 196/96 sobre pesquisa envolvendo seres humanos. 0 projeto foi encaminhado à Comissão de Ética da Secretaria de Saúde do Município de Pelotas, conforme já foi relatado anteriormente e cumpridas as exigências feitas pelo Secretário de Saúde.

\section{ANÁLISE DE DADOS NA OBSERVAÇÃO PARTICIPANTE}

Sabe-se que os pesquisadores costumam encontrar obstáculos quando partem para a análise dos dados recolhidos no campo, sendo um deles o perigo da compreensão espontânea, como se o real se mostrasse sem transparência para o pesquisador. Além disso, o pesquisador pode ater-se ao método e às técnicas, esquecendo-se do que está presente no material. Há, ainda , outro obstáculo: é a dificuldade de se associar teoria e conceitos muito abstratos com os dados recolhidos no campo ${ }^{3}$.

Assim, neste estudo, os dados foram analisados de maneira indutiva, num primeiro momento, seguindose as etapas descritas por Minayo ${ }^{3}$ "buscar a partir do próprio material coletado a descoberta da pesquisa, administrando provas, comprovando-as, refutando-as, ou levantando novas provas; ampliando os contextos culturais e ultrapassando o nível das mensagens" ${ }^{13: 198}$. Tínhamos as categorias pré-estabelecidas, referentes ao quadro teórico, ou seja, pela Teoria Bioecológica de Bronfenbrenner, os quatro núcleos: tempo, pessoa, processo e contexto e seus níveis e, após sucessivas leituras da descrição das observações e entrevistas, foram sendo relacionados os dados aos núcleos. 
Na primeira etapa, ou pré-análise ${ }^{3}$, foram escolhidos os documentos a serem analisados, tendo como base a questão da pesquisa e os objetivos traçados inicialmente, reavaliando-os ao longo das análises. Esta etapa foi desenvolvida através da leitura flutuante do material coletado e da constituição do corpus, que se refere à organização do material, considerando algumas normas de validade, ou seja, exaustividade, representatividade, homogeneidade, pertinência ${ }^{3}$.

$\mathrm{Na}$ fase de pré-análise, determinamos, ainda, a palavra-chave ou frase, a unidade de contexto, os recortes, a modalidade de codificação, categorização e os conceitos teóricos gerais que orientaram a análise, conforme o quadro 1. A codificação foi realizada fazendo-se as anotações à margem dos relatos digitados.

$\mathrm{Na}$ segunda etapa, ou exploração do material'3 , trabalhamos com a transformação dos dados brutos, tentando alcançar o núcleo da compreensão do texto. Iniciou-se recortando as palavras ou frases, conforme 0 estabelecido na pré-análise. Após a verificação de sua consistência, classificamos os dados em categorias empíricas. Entre estas surgiram: saúde é poder trabalhar; trabalho rural como identidade do colono; riscos e potencialidades para o desenvolvimento individual e familial; cuidado familial em situação de doença, e 0 descuidado; fatores que favoreceram/dificultaram a comunicação do colono/família.

Num momento seguinte, buscamos uma maior aproximação entre o material coletado e analisado (categorias empíricas) e o referencial do estudo, utilizando-se métodos indutivos e dedutivos de análise. Para exemplificar: a categoria trabalho (indutiva), ao analisá-la à luz da teoria de Bronfenbrenner, foi constatado que representava uma atividade molar, com toda sua abrangência e conseqüências. As categorias das forças das pressões econômicas e as decisões políticas passaram a compor o macrossistema, ou seja, as relações que existiam entre as famílias rurais e essas políticas; os programas políticos (agrário, social e de saúde), de cujas decisões o colono/família não participava, passaram a compor o exossistema; as relações próximas do colono/ família com as instituições de saúde, religiosas, educacionais da comunidade Sol passaram a compor 0 mesossistema e o colono e sua família, um microssistema.

As posições das pessoas no ambiente, ou seja, as mudanças de papel (pai, mãe, avó, doente, sadio, estudante, etc.) constituíram as transições ecológicas. Assim, aos poucos, o referencial teórico, abstrato, foi "criando forma, vida e movimento" a partir das famílias da comunidade Sol.

Embora tendo-se iniciado com categorias pré-estabelecidas, o estudo permitiu trazer à tona outras categorias tais como: o vínculo apoiador, os riscos e as potencialidades do desenvolvimento da pessoa/família/ comunidade, a participação, comunicação e conhecimento interambiente.

Novos conceitos foram agregados com base no estudo, ampliando o novo quadro referencial, onde saúde, doença, ruralidade e desenvolvimento humano ecológico, pessoas/famílias se articulam, assumindo dimensões ora concretas, ora teóricas. Esse movimento entre teoria e prática, subjetividade e objetividade, acomodação progressiva e mútua entre o ser humano e o seu ambiente, o cuidado e o descuidado constitui importantes inter-relações, que emergiram deste estudo, conforme a abordagem Bioecológica. Esta constatação foi possível, através da observação participante associada aos outros métodos.

\section{CONCLUSÃO}

Com base na compreensão das relações do ser humano/família rural com as políticas públicas (social, de saúde e econômicas), neste estudo a observação participante mostrou-se adequada para compreender 0 viver, o adoecer e o cuidar das famílias de uma comunidade rural tendo em vista que foi possível acompanhá-la em diversas oportunidades, assim como aplicar outros instrumentos na coleta de dados, como por exemplo a entrevista, o que possibilitou visualizar o contexto das relações destas famílias.

Ao se utilizar a observação participante, cumpre assinalar que o ideal é dispor de tempo para realizá-la, pois os fenômenos acontecem no decorrer do tempo, e este pode auxiliar a compor a compreensão. Também 
porque algumas comunidades são mais "fechadas". Então, somente e com o passar do tempo os informantes, confiando no pesquisador, expõem os fatos e atos que ocorrem com as famílias e as comunidades, ou seja, que eram veladas.

ABSTRACT: This paper tries to show the participant observation as a method of data collecting in studies which had as a general goal the comprehension of family living, getting sick and caring in a rural area in Southern Brazil. It is very important to the health care provider to know the way rural families live, establis ties and close relationships with the community in which the main interaction unity is linked by interpersonal relationships as the family, neighbors and friends.

KEY WORDS: P articipant observation; R ural family; Methodoloy

RESUMEN: Este artículo tienta demostrar la observación participante como metodologia de colecta de datos de uma pesquisa que tuvo como objetivo general comprender el vivir,el enfermar y el cuidar de famílias de uma comunidad rural del extremo sur de Brasil. Ésta metodologia se mostro apropiada pués permitió establecer lazos y relaciones estrechas com la comunidad em la qual, la principal unidad de integración está ligada por relaciones personales más próximas como la família, los vecinos y los amigos.

PALABRAS CLAVES: Observación participante; Família rural; Metodologia

\section{REFERÊNCIAS}

1 Bronfenbrenner, U. A ecologia do desenvolvimento humano: experimentos naturais e planejados. Porto Alegre: Artes Médicas; 1979/1996.

2 Bronfenbrenner, U. Ecological systems theory. In: Annals of Child development. Greenwich: 1989; 6:187-249.

3 Minayo, M.C.S. O desafio do conhecimento: pesquisa qualitativa em saúde. 5.ed. São Paulo: HUCITEC; Rio de J aneiro: ABRASC0; 1998.

4 Minayo, M.C.S., organizadora. Pesquisa social: teoria, método e criatividade. 11.ed. Petrópolis: Vozes; 1999.

5 Minayo, M.C.S.; Sanches, O. Quantitativo-qualitativo: oposição ou complementaridade? Cad. Saúde Publ., 1993; $9(2): 239-62$.

6 Holloway, I.; Wheeler, S. Qualitative research for nurses. Oxford: Blackwell Science; 1996.

7 Hart, Z.M.A., organizador. Avaliação em saúde: dos modelos conceituais à prática na análise da implantação de programas. Rio de J aneiro: Fiocruz; 1997.

8 Schwart, M.S.; Schwart, C.G. P roblems in participant observation. In: McCall G.J ., Simmons J .C., organizadores. Issues in participant observation, a text and Reader. Massachuttes: Addison-Wesley; 1969.

9 Haguette, T.M.F. Metodologias qualitativas na sociologia. 5.ed. Petrópolis: Vozes; 1997.

10 Leininger, M.M. Qualitative research methods in nursing. Orlando: Grune \& Stratton, 1985. Cap. 3, p. 33-71.

11 Leininger, M.M. Culture care diversity and universality: a theory of nursing. New York: National League for Nursing, 1991. p.73-117.

12 Bielemann, V.L.M. O ser com câncer: uma experiência em família. [dissertação] Florianópolis [SC]: Programa de Pósgraduação em Enfermagem, Universidade, Universidade Federal de Santa Catarina; 1997.

13 Denardin Budó, M.L. Cuidando e sendo cuidado: um modelo cultural de suporte à saúde em comunidade rural de descendentes de imigrantes italianos. [dissertação] Santa Maria [RS]: Pós-Graduação em Extensão Rural, Universidade Federal de Santa Maria; 1994.

14 Patrício, Z.M.A. Prática do cuidar/cuidado à família de adolescente grávida solteira e seu recém-nascido através do marco conceitual de enfermagem de enfoque sócio-cultural. [dissertação] Florianópolis [SC]: Programa de Pósgraduação em Enfermagem, Universidade Federal de Santa Catarina;1990. 
15 Boehs, A. A prática do cuidado ao recém nascido e sua família, baseada na teoria transcultural de Leininger e na teoria do desenvolvimento da família. [dissertação] Florianópolis [SC ]: Programa de Pós-graduação em Enfermagem, Universidade Federal de Santa Catarina;1990.

16 Boehs, A. Os movimentos de aproximação e distanciamento entre os sistemas de cuidado familiar e profissional. [Tese de Doutorado] Florianópolis: Curso de Pós-graduação em Enfermagem, Universidade Federal de Santa Catarina; 2001.

17 Schwart, E. Família teuto-gaúcha: o cuidado entre possibilidades e limites. [dissertação] F lorianópolis [SC]: Programa de Pós-Graduação em Enfermagem, Universidade Federal de Santa Catarina;1998.

18 Sandelowski, M. Sample size im qualitative research. Res. Nurs. \& Health, 1995; (18):179-83.

Recebido em 12/12/02 aceito em 15/03/03

Endereço do autor:

Eda Schwart

Avenida Fernando Osório, 5189 B

CEP 96065-000 - Pelotas - RS

E-mail: eschwartz@ terra.com.br 